\title{
Article
}

\section{The Impact of Information Systems Implementation in the Greek Manufacturing Enterprises}

\author{
Paraskevi Kapetanopoulou ${ }^{1, \dagger}$, Antigoni Kouroutzi ${ }^{2, \dagger}$ and Sofia Anastasiadou ${ }^{3, *,+}$ \\ 1 Department of Mechanical Engineering, Aristotle University of Thessaloniki, 54124 Thessaloniki, Greece; \\ vkapetan@meng.auth.gr \\ 2 Faculty of Economics and Management, Open University of Cyprus, Latsia 2220, Cyprus; \\ antikourout@gmail.com \\ 3 Department of Midwifery, School of Health Sciences, University of Western Macedonia, \\ 50100 Ptolemaida, Greece \\ * Correspondence: sanastasiadou@uowm.gr \\ + These authors contributed equally to this work.
}

Citation: Kapetanopoulou, P.; Kouroutzi, A.; Anastasiadou, S. The Impact of Information Systems Implementation in the Greek Manufacturing Enterprises. Appl. Sci. 2021, 11, 11781. https://doi.org/ 10.3390/app112411781

Academic Editor: Luis Javier Garcia Villalba

Received: 2 November 2021

Accepted: 1 December 2021

Published: 11 December 2021

Publisher's Note: MDPI stays neutral with regard to jurisdictional claims in published maps and institutional affiliations.

Copyright: (c) 2021 by the authors. Licensee MDPI, Basel, Switzerland. This article is an open access article distributed under the terms and conditions of the Creative Commons Attribution (CC BY) license (https:// creativecommons.org/licenses/by/ $4.0 /)$.

\begin{abstract}
Purpose-The purpose of this study is to assess the impact of Information Systems (ISs) implementation in Greek industry. The main issues that are explored through this survey in regards to IS adoption are the financial and nonfinancial benefits that are derived due to IS adoption. The study also investigates the effect that IS adoption had in several business areas in regards to the factor of financial performance. Design/methodology/approach-The survey that was conducted was questionnaire based. Of the 96 valid responses that were received, 83 of them implemented at least one IS. Those 83 responses were analyzed statistically. Several statistical tools were used for that, such as: nonparametric $\chi^{2}$ tests for homogeneity, Cronbach Alpha method for the reliability of the questionnaire, and Mann-Whitney U tests. Findings-The results suggest that the majority of industry in Greece has implemented-at least-the ERP to conduct their business. In addition, most of them use a combination of not more than three ISs. The respondents are also satisfied by the financial impact of IS adoption. Inventory and warehouse management, along with customer service, were most positively affected by IS implementation. On the other hand, returned products reduction and the relationship with the suppliers were less positively affected by IS adoption. Research limitation/implications-The study has a limitation of being conducted in North Greece and not in the whole country. Originality/value-The paper constitutes an empirical research in regarding the financial and nonfinancial contribution of IS adoption in Greek industry. There are rather limited studies that have been conducted in Greece regarding IS implementation and the impact it poses in business affairs. The financial crisis along with the political instability that Greece has faced in the last decade makes it interesting to explore the influence of IS adoption in manufacturing enterprises. Usually, those studies are conducted in more developed countries where the financial and political environment is more stable.
\end{abstract}

Keywords: information systems/technology; manufacturing; impact; benefits; financial effect

\section{Introduction}

In today's new economy, Information Systems (ISs) or Technology (IT) are widely used, and they are mainly the reason why industries and businesses have evolved and changed rapidly [1-3]. For example, big data is a very prominent IT technology for a variety of fields, such as computing, economics, business, agriculture, accounting, etc. [4-11]. The global competition that already exists among manufacturing firms will continue to be intensive into the future. This has led organizations to implement IT in order to gain advantages against their competitors. IS adoption may have induced dramatic changes in business internal processes by radically altering structures, strategies, and decisionmaking processes $[3,12]$. Globalization has led to an era where the competition has shifted 
from local to global, in other words from company against company to one supply chain against another supply chain [13]. Businesses have recognized IT implementation as a critical factor that can contribute not only to an independent companies performance but also to the supply chain performance-in which the company might participate-as a whole $[13,14]$. In [15], the authors focused on IS implementation in complex settings from a sociomaterial perspective and proposed that higher levels of motivation and intentionality are related to higher chances of successful implementation. Due to IS, enterprises were able to manage the abundance of information among their departments and also share them with their collaborators in the supply chain in a timely, accurate, and reliable way [14]. Through IS, companies and supply chains try to achieve better in several areas such as competitive advantage, production planning, inventory management, distribution management, customer satisfaction and loyalty, financial gains and other-financial or nonfinancial-benefits that can be derived by the use of advanced systems [12-14]. In addition, the use of social networking platforms and the formulation of communities [16] further necessitate the extensive research on IT for businesses, as more and more companies make extensive use of data collected through social networks and communities to improve their customer satisfaction and increase their profit. Companies have realized that through IS they have the opportunity to implement important innovations in their processes, increased flexibility in information generation, and also improved decisions based on timely and reliable information [17].

Even the early years of IS implementation, researchers considered it critically important to investigate the benefits and the impact ISs might have in the business performance. The first studies were not very promising regarding the positive and statistically significant relation between the Information and Communications Technology (ICT) adoption and business performance [18], which made managers wonder whether they should invest in them. That impression has shifted since the mid-1990s, where research studies showed that there is significant positive relation between ICT investment and some aspects of business performance [19].

Since then, there were several studies that tried to assess the effects of IS implementation not only in companies but also in supply chains performances. Several literature reviews have noted the need for empirical research and in particular for survey-based studies that could provide answers regarding the impact of IS adoption in several aspects of industry. In [20], the authors call for more studies that would research the effects of ERP implementation on a company's competitive advantage. In [21], the authors call for further studies in order to investigate several types of IT applications and their respective impacts on businesses. As the awareness of the advantages of IT adoption is growing up, companies consider it important to come to a realization regarding the impact of IT on the firm's performance [14]. Studies regarding the long-term benefits of the ICT adoption could prove to be crucial to convince the Small-Medium Enterprises (SMEs) owners to apply an ICT system if it is proven that the benefits can overcome the additional costs of implementation, training, etc. [3]. Several studies call for studies regarding the impact and benefits of ERP implementation $[13,22,23]$ as well as the effects of Supply Chain Management (SCM) on a company's performance $[13,23]$. They also call for a focus on investigating the effects of performance in specific business areas such as financial, marketing, customer-based performance, etc. [13]. Other studies call for further research regarding the impact of CRM in organizational performance and innovational capabilities of firms [24,25].

The motivation behind the research presented in this paper was the need to assess the impact and contribution of IS implementation in several aspects of business performance in manufacturing companies in North Greece. In other words, the paper is trying to determine whether Greek and multinational companies which operate in Greece benefitedfinancially and non-financially - from IS adoption. The financial crisis that hit the country the last decade has affected-more or less-Greek and multinational enterprises. Beyond that, Greece is close to other countries with weaker economies and lower taxes. That fact has driven several companies to transfer their facilities and their administration to 
countries such as Bulgaria in order to gain more benefits from their operations. Under those circumstances, it was interesting for the authors of this paper to know if the companies facilitated in this area gained any benefits from using IS.

Therefore, it is natural to pose the following broad hypothesis:

Hypothesis 1 (H1). The manufacturing companies in North Greece that have adopted —at least one-IS have declared that the implementation of IS has had a positive impact in their business.

The main objective of this research is to obtain answers-positive or negativeregarding the above general hypothesis and gain a better understanding of the relevant issues in North Greek industry, including Greek and multinational manufacturers that facilitate that area. That objective would be possible to be determined through an extensive questionnaire-based survey about IS in the manufacturing sector. A parallel objective is to contribute to the knowledge about the kind of influence IS adoption had in business performance in European industry.

This empirical research contributes to filling the research gaps which were described previously by making the following contributions:

- It empirically investigates which kind of IS or ISs Greek companies have adopted to conduct their business.

- It determines whether IS implementation is considered profitable.

- It also determines how (positively or negatively) several management departments were affected as the companies apply more innovative technologies such as ISs.

- It also tries to determine the contribution (positive or negative) of IS adoption in several factors that were considered important.

- It investigates whether there are factors that affect the impact and contribution of IS implementation in several aspects of business process. The companies were divided into two groups regarding the profitability of IS adoption: those with high profitability and those with medium profitability. The two groups were compared regarding the impact and contribution of IS adoption.

The next section presents a literature review of the use of IS and the benefits that it might bring to businesses as well as presenting the research hypotheses. Section 3 describes the research methodology and the data collection process. Section 4 contains the research results, and the final section summarizes the main conclusions of this research along with our propositions for future research.

\section{Literature Review and Research Hypotheses}

Since the early days of IS implementation, several researchers have tried to determine the financial and nonfinancial benefits of modern-era technologies. Their goal was to find out if ICT positively affects the way manufacturers conduct their business and to what extent. They mostly agree that enterprises were more or less positively affected by the use of new technologies. Even an upgrade of a basic IT system to a more advanced one can lead to additional benefits. SMEs can gain much from ISs that would help their strategy and their management as they can provide better customer service, faster communication with customers, better distribution network to distribute their products, etc. The internet helped a lot to that extent, as it is easier for a company to reach the customers. A very important element of ICTs is that they increase systems integration, which greatly helps the managers run their departments based on a combination of information [21]. In [26], the authors suggest that in the supplier selection process the benefits derived from IS implementation are mostly nonfinancial and more related to management decision. In the study conducted in [27], several variables were measured that can be considered as parts of different departments within an organization.

The managers of those departments—such as Production, Inventory, Customer, Supply, Distribution, Warehouse, etc.- - constantly try to find ways to improve the way they manage the whole department. They also try to determine which parts of the department 
need more attention or which parts did better [14]. In [20], the authors researched the benefits of ERP regarding the firm's performance. Among other areas of focus, they also studied the effects of ERP into the inventory levels, interaction with customers, and inventory and supplier management [20]. In [28], the authors' research on performance measured those regarding customer service and satisfaction. Therefore, the following hypothesis is proposed:

Hypothesis 2 (H2). IS adoption has a positive impact on management (Supply management, Production management, Distribution management, Warehouse management, and Inventory management) and customer service.

Several studies have tried to determine which areas in a company were affected (positively or negatively) by the implementation of IS. In [28], the authors try to determine whether IT influenced a positively competitive advantage which might positively influence the relationship with the suppliers and the customers. In the current market, a company deals simultaneously with various suppliers that can be culturally different and located at several geographic places of our planet. At the same time, customers constantly seek and demand a constantly increasingly high level of satisfaction. ISs, besides many other benefits, can also provide more negotiation power to the suppliers as they deal with their customers. The stakeholders that are related to a company can all be benefited in several areas of their business as the use of IS enables deeper, more stable, and more relevant relationships between them [26]. ERP can benefit the performance of an organization in several areas such as reduced cost, improved productivity, customer services, and quality. ERP can also lead in better resource management, and it can help managers improve their decision making and planning, etc. [12,20,29]. In [30], the authors tried to determine whether companies benefited by IS adoption regarding cost saving and better coordination with the suppliers and the customers, as well as if it helped keep the inventory level lower and determine the cost more accurately. IS adoption can increase productivity and improve inventory control. It can also lead to faster delivery times and cost reduction-the latter benefiting several departments in a firm. With the use of IS, better resource management can improve decision making and planning which helps management, etc. $[12,20,29]$. In [30], the authors tried to determine whether the companies benefited from IS adoption regarding cost saving, keeping inventory level lower, being able to determine the cost more accurately, and better coordination with the suppliers and the customers. IS adoption can increase productivity, improve inventory control, and lead to faster delivery times and cost reduction - the latter benefits several departments in a firm-and products can reach higher levels [12,21]. It is considered that SCM activities are strongly associated with several aspects of business performance such as operating cost reduction, revenue growth, etc. [31]. Taking all this into consideration, we pose the following hypotheses that are focused in areas that the authors subjectively considered more important, as they acknowledge that there are many others that could have been chosen to examine their effects that are derived from IS adoption.

The following hypotheses can be posed:

Hypothesis 3a (H3a). IS adoption positively affected the competitive advantage.

Hypothesis $\mathbf{3 b}(\mathbf{H} 3 \mathbf{b})$. IS adoption positively affected the production process.

Hypothesis $3 \mathbf{c}(\mathbf{H} 3 \mathbf{c})$. IS adoption led to less returned products.

Hypothesis $3 \mathbf{d}(\mathbf{H} 3 \mathbf{d})$. IS adoption helped the company build a better relationship with the suppliers.

Hypothesis $3 \mathbf{e}(\mathbf{H} 3 \mathbf{e})$. IS adoption led to cost reduction.

Hypothesis $3 \mathbf{f}(\mathbf{H} 3 \mathbf{f})$. IS adoption led to faster customer service.

Hypothesis $3 \mathbf{g}(\mathbf{H} 3 \mathbf{g})$. IS adoption helped the companies maintain their clientele. 
More and more companies implement ISs because they hope and expect that they will benefit financially. They also hope to be able to maximize those benefits by using proper managerial techniques. It is not a surprise that quite frequently, several studies' main subject is to assess the accountability of investments in ISs [32]. In [32], the authors tried to determine the relationship between the postimplementation practices of ERP and the financial performance. Similarly, a study conducted in [33] by authors in several organizations focus more on determining the financial impacts-besides other impactsand the profitability of ERP, SCM, and CRM at the postimplementation stage of the system. The results of that study were mixed. They confirmed that profitability and other financial metrics are positively influenced by ERP and SCM implementation but that does not apply to the CRM adopters. In [25], the authors also studied whether the relationship between CRM adoption and organizations financial performance is positive, and they concluded that there is not a positive relationship, which is similar to the authors' study in [33]. In [27], the authors included financial performance among the performance measures they researched in their study, among others. Thus, the following hypothesis is formed:

Hypothesis 4 (H4). IS adoption has a positive impact on a company's profitability.

The former hypothesis has been actually verified in a previously published paper by the authors in [34]. It was derived by the study that $92.7 \%$ of the companies stated that IS adoption was profitable at a high or at least a satisfactory level. Based on that, two prominent different groups of companies were identified regarding the level of profitability they obtained due to IS adoption: those which consider that IS adoption led their companies to a high level of profitability (IS1) and those where their company managed to accomplish medium level of profitability (IS2) due to IS adoption. Through the current research, there is an effort to assess whether there are statistically significant differences between these two groups regarding the impact and contribution of IS adoption in a company's several aspects. Thus, two prominent hypotheses were formed:

Hypothesis 5a (H5a). "The higher the profitability, the more positive the impact of IS adoption which is followed by a statistically significant difference between the two groups (IS1 and IS2) in-Supply, Production, Distribution, Warehouse and Inventory-Management, respectively, as well as in Customer service."

Hypothesis $\mathbf{5 b}(\mathbf{H} \mathbf{5 b})$. "The higher the profitability, the more positive the contribution of IS adoption which is followed by a statistically significant difference between the two groups (IS1 and IS2) in Competitive advantage, Production process, Returned products reduction, Relationship with the suppliers, Cost reduction, Fastest Customer service, and Maintain clientele, respectively."

\section{Research Methodology and Data Collection}

The study was conducted on manufacturing companies-public and private-that are active in North Greece on the districts of Macedonia and Thrace. The population for the study was based on the companies which are active-producing-on those Greek areas. The list of the companies was obtained from ICAP's Greek Financial Directory of the year 2017 [35], volume 1: industry [35]. ICAP's directory includes detailed listings of manufacturing companies-Greek and multinationals-in Greece. The questionnaire was sent to several enterprises of that list, excluding those that according to ICAP's directory [35] were listed as "Very Small". A total of 184 companies were instructed to answer the questionnaire that was sent to them. We received 96 replies by the end of January 2019.

According to the authors in [36], the questionnaire was short in order to achieve the maximum response rate. The questionnaire consisted of 15 questions, 13 of which were closed-ended questions and the last two of them were open questions that the respondents could fill with additional comments. The objective of the penultimate question was to determine the respondents' job title on the company, while the last question was asking about their thoughts regarding IS and Supply Chain (SC) in Greek industry. Of the 13 
close-end questions, the first two were addressed to all respondents. The second question tried to determine whether the enterprises were using a form of Information System (IS) or not. Depending on the answer of that second question-yes or no-the respondents were instructed to either follow the natural course of the questionnaire or to proceed to the tenth question-its objective was to determine which reasons would prevent a company from investing in an IS.

The survey instrument was developed based on the extensive review of the current literature, which was delineated in Section 2. In order to assess the questionnaire's clarity, comprehensiveness, and overall suitability, the questionnaire was e-mailed in a pilot sample of five experts regarding IS in order to pretest it.The authors of this study took into consideration their suggestions for the few amendments that were applied on the questionnaire. After those changes it was ready to be sent to the manufacturing enterprises. The questionnaire, which was accompanied by a cover letter, was sent in November 2018 to 184 manufacturing enterprises to be filled out on the web. The cover letter provided a brief description of the research project, and in addition, it provided assurance that any information obtained from the companies that would participate in the study would be treated as confidential. The majority of the e-mail addresses were found in the ICAP directory, while the rest were found on the General Commercial Registry's site [37], as well as the Exporters' Association of Northern Greece's site [38]. All the companies were contacted by phone to verify the e-mail addresses we had found but also to inform them about the research. Three weeks after the first invitation, the questionnaire was sent againvia e-mail - to the companies that had not responded and they were also informed again by phone, in order to improve the response rate. The same procedure was followed after the Christmas holidays once again.

Strict checks were performed in the returned questionnaire in order to ensure its completeness and consistency. According to the checks, the total amount of the questionnaires that were answered in a way found to be valid and usable for further analysis put the overall response rate at $52.17 \%$ percent.

The sample was also checked for representativeness with respect to industry sector and also the district being facilitated. Regarding the industry sector, the $X^{2}$ goodness-of-fit test shows that the sectorial representation of the sample does not differ significantly from that observed in the total population of manufacturing enterprises in North Greece; the $p$-value of the test was 0.813 . Accordingly, the $X^{2}$ goodness-of-fit test regarding the district representation showed that the sample did not differ significantly from that observed in the total population of manufacturing enterprises in North Greece; the $p$-value of the test was 0.717 . The $p$-value is considered as the minimal significance level for rejection or the null hypothesis [39].

The questionnaire was also tested with the Cronbach Alpha method for its reliability. The Cronbach Alpha index value was found to be equal to 0.856 , which is considered to be a very good value for validation [40-47].

\section{Results and Discussion}

As mentioned in Section 3, a number of 96 companies responded to the questionnaire. A great number of companies, 83 out of 96 , stated that they have already adopted an Information System (IS). All the results and discussion that are presented in the next sections are about these 83 companies that have implemented ISs. The software that was used for the statistical data processing is the IBM SPSS Statistics v. 23

\subsection{General Characteristics}

Figure 1 shows the profile of the respondents with respect to the industry sector which the company they work for operates. As it is noticeable approximately one third of the companies operate in the food sector. The "Other" in the Figure 1 represents industry sectors with no more than five responses. 


\section{Profile of the Companies: Industry Sector}

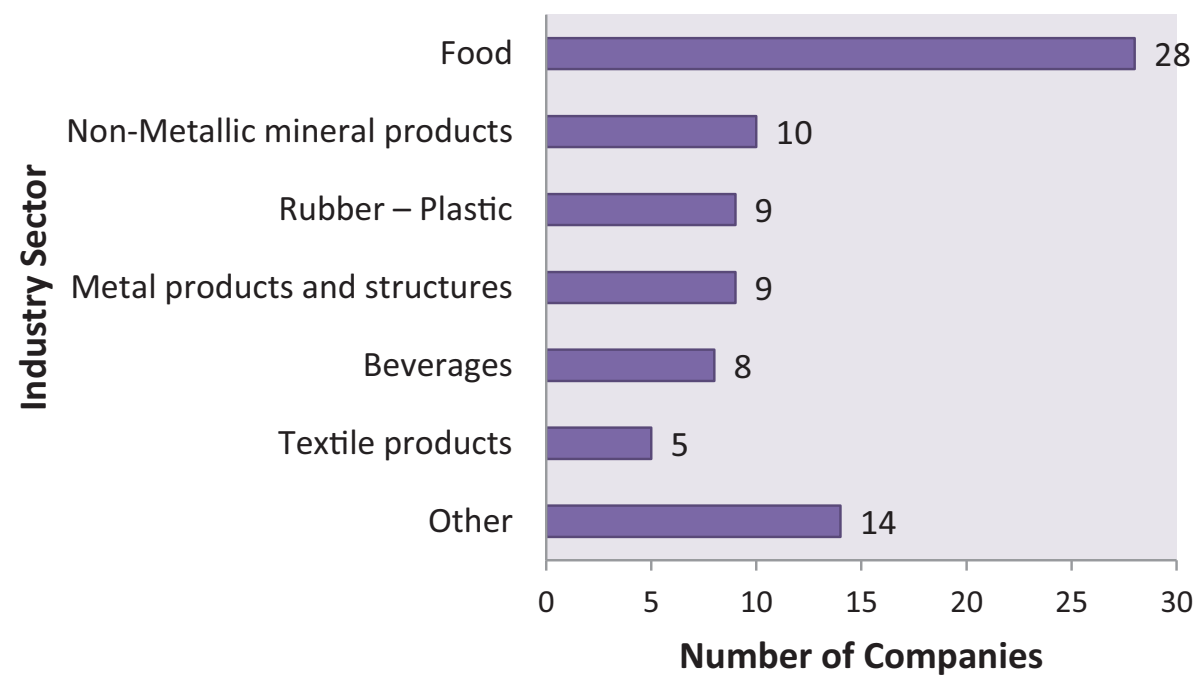

Figure 1. Profile of the companies: Industry sector.

\subsubsection{Information Systems (ISs) and Future Investment}

Although 83 companies stated that they use at least one IS, one company did not specify which system/systems she uses. The responses of those 82 companies regarding the IS they have implemented are presented in Figure 2. It is noted that the percentages in this figure sum up to much more than 100 percent because most companies use more than one system. A great majority (85.4\%) of the companies use the ERP system and the percentages for CRM, OMS, and WMS range between $35.4 \%$ and $39 \%$. One third of the companies (32.9\%) use only one system, of whom $88.9 \%$ use ERP. In addition, $68.3 \%$ of the respondents use a combination of not more than three systems combined. It is worth mentioning that only a small number of companies use SCM $(13.4 \%)$ in order to conduct their business. As the competition shifts from individual firms to supply chains one could expect that SCM would be more in use in order to help manufacturers to successfully manage their supply chain.

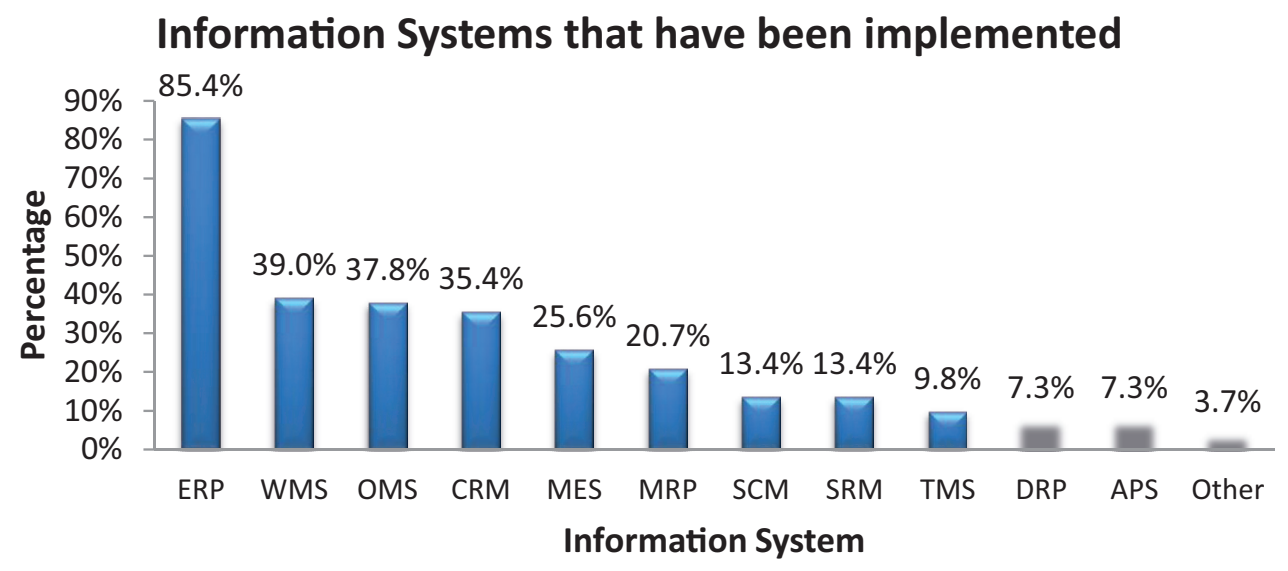

Figure 2. Information systems that have been implemented.

As it was also referenced in the research conducted by the authors in [34], there are similarities and differences in regards of IS adoption with the research that was conducted by authors in [30]. The percentage of the companies they use IS in the current study is almost 75\% higher than the one in [30]. On the other hand, fewer companies use WMS, MRP, SCM, SRM and APS in the current research compared to those they use them in [30]. 
Although the great majority of the companies $(90.4 \%)$ have invested in an IS in the last decade [34], 62.7\% of them have declared that are eager to invest in a new IS in the prompt future. According to the authors in [20], research in Korean manufacturing firms that have already implemented a form of ERP most of the firms were in the process of implementing, planning, or considering to implement various extensions to their ERP system. Among them were CRM - greater percentage-SCM, APS as well as modules that would make easier to tie up their customers or suppliers to their ERP systems. That means that just because they already have a system they don't stop investing in additions that they will improve the way they conduct their business.

\subsubsection{Impact of IS Adoption}

The companies that use IS were asked to assess the impact of IS implementation insupply, production, distribution, warehouse, and inventory-management. In addition to those variables, they assessed the impact of IS adoption in "Customer service" since one of the ulterior goals of management is to satisfy the customers with their products or services. A five-point Likert scale was used to determine the positivity or negativity of the effects of IS adoption using 1 as "very negative" and 5 as "very positive". The average ratings are shown in Figure 3 where it is easily visible that the impact is positive since they are all above 4. "Inventory management", "Customer service" and "Warehouse management" were the ones that were more positively affected by the use of IS in business. On the other hand "Distribution management" was less positively affected but after-all it was positively affected.

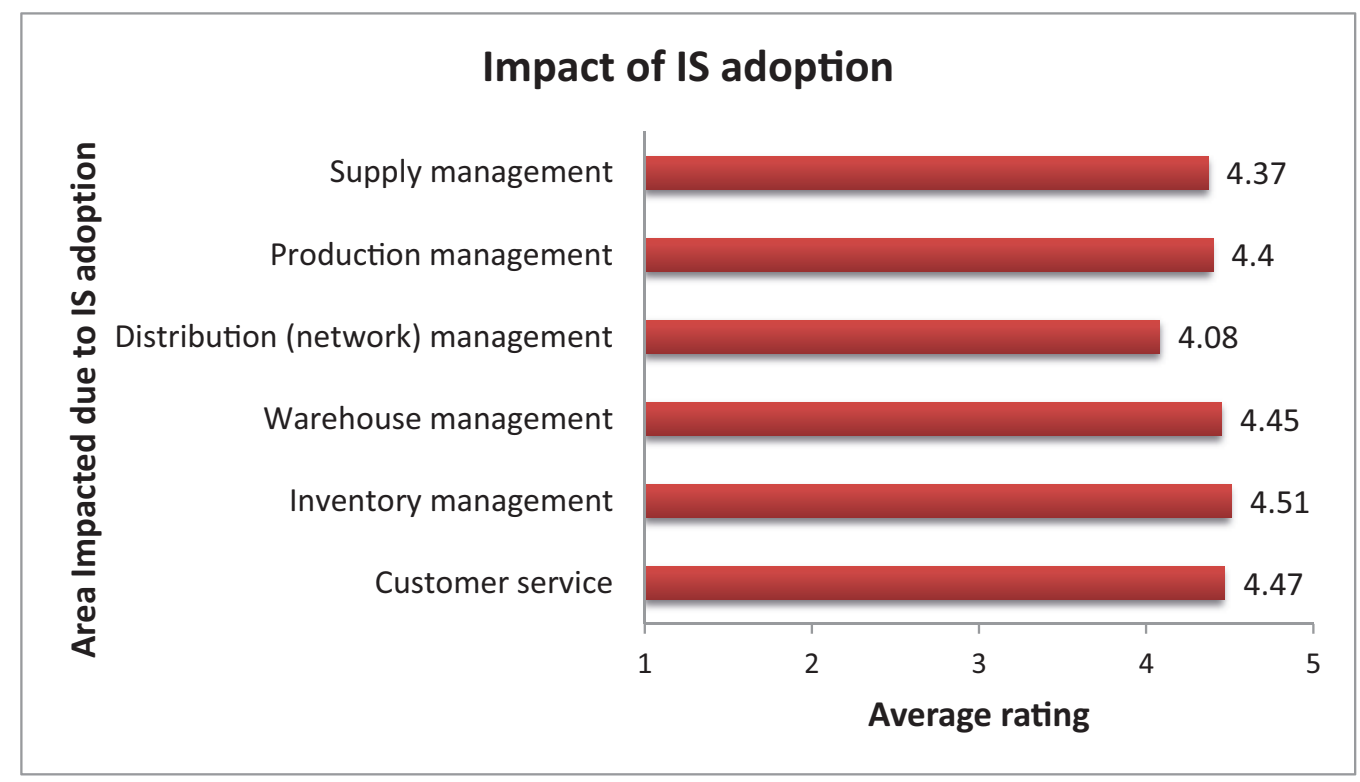

Figure 3. Impact of IS adoption.

Several studies have tried to determine the benefits of ICT into business, or in other words, whether IS positively affected the way manufacturers conduct their business. The general feeling is that IS helped companies a lot in several aspects regarding their business. The benefits that can be derived by IS adoption could be the following: better customer service, better distribution, increased productivity, better inventory control, faster delivery times, cost reduction, etc. [21]. According to authors in [14], the respondents somewhat agree that IT helped into production management while the effect on Inventory management was lower. In their study [14], the authors used a seven-point Likert scale to measure several variables that can be considered as parts of several other elements that can be appointed to different departments of management such as Production, Inventory, Customer, Supply, Distribution, and Warehouse management. The average scores in all variables were above 4 (neutral), which mean that the respondents agree that IT helped 
them to better support their business in several areas [14]. In [26], the authors suggest that in the supplier selection process the benefits derived from IS implementation are mostly nonfinancial and more related to management decisions. In [21], the authors among other things, exploited the benefits of ERP in the organizational performance by using a five-point Likert scale (1: "not at all", 5: "a great extent"). Among the characteristics, the respondents had to grade were: lower inventory levels, improved interaction with customers, inventory management, and supplier management/procurement. In all these characteristics, the average was between 3 and 3.5 .

\subsubsection{Contribution of IS Adoption}

In the eleventh question of the questionnaire, the respondents were asked to determine the contribution-positive or negative-of IS adoption in several aspects of their business such as: Competitive advantage, Production Process, Returned products reduction, Relationship with the Suppliers, Cost reduction, Faster Customer Service, and Maintain clientele. A five-point Likert scale was used so the respondents could rate their answers with 1 - "very negative" - and 5-"very positive". Figure 4 presents the average ratings of their responses. It seems that the contribution of IS implementation was more positive in "Faster Customer service". Customer service is the act of taking care of the customer's needs by providing and delivering professional, helpful, high quality service and assistance before, during, and after the customer's requirements are met. Customer service is meeting the needs and desires of any customer. The contribution of IS adoption was less positive in "Returned products reduction" followed by the "Relationship with the suppliers" as a close second. According to the results (Figure 4), four hypotheses were definitely verified $(\mathrm{H} 3 \mathrm{a}-\mathrm{d})$ as IS implementation positively affected competitive advantage and production process. It also leads to cost reduction and faster customer service. In addition the hypothesis $\mathrm{H} 3 \mathrm{e}$ can be considered as verified as the average score is 3.90 which is close to 4 . That means that the use of IS helped the companies to maintain their clientele. Sure there is margin for improvement as there is to the previous four hypotheses that were verified. Two hypotheses (H3c, H3d) although they had no negative average score they still were pretty low for one to say that they were verified. It seems more that the respondents ween't very sure whether IS adoption leads to less returned products or to better relationship with the suppliers and their response was closer to neutral. At least they don't consider that it had a negative effect. Those areas might need more attention from managers as it seems that there is large margin for improvement.

In several studies, the researchers try to determine which specific areas were influenced by IS adoption. In [28], the authors verified their hypotheses in the one percent level of significance: when the $p$-value is lower than 1 the null hypothesis cannot be rejected. Among those hypotheses were "H1: IT positively influences SCM competitive advantage", "H6: SCM competitive advantage positively influences supplier relationship", and "H7: SCM competitive advantage positively influences customer relationship". Good relationship with the customers might help the company to maintain the clientele as there is a greater possibility for a satisfied customer to come back again. The relationship with the suppliers in the current research is the one that is less positively affected by IS adoption, which means there is room for improvement [28]. In [48], the authors using data from several areas (USA, Europe, and New Zeland) found out a positive relationship between information sharing capability, which derives from IS adoption, and the relationship between buyer and supplier. The latter relationship has also a positive effect on financial performance [31]. In [30], the authors used a five-point Likert scale (1: "not at all", 5: "a lot") to determine "how much the companies were benefited from using ISs". Among the variables they examined were the following ones that are close to some that are examined in the current research: cost saving, reduced inventory level, more accurate costing, increased coordination with suppliers, and increased coordination with customers. The mean in all variables is between 3 and 4 . In [21], the authors, among other things, exploited the benefits of ERP in the organizational performance by using a five-point Likert scale (1: "not at all", 5: "a great extent"). Among 
the characteristics, the respondents had to grade were: improved interaction with customers, improved interaction with suppliers, reduced direct operating costs, financial management, and decreased information technology costs. In all these characteristics, the average was between 3 and 3.5. Manager's determination to implement SCM can lead Indian SMEs into improving areas such as customer service and satisfaction [27].

\section{Contribution of IS adoption}

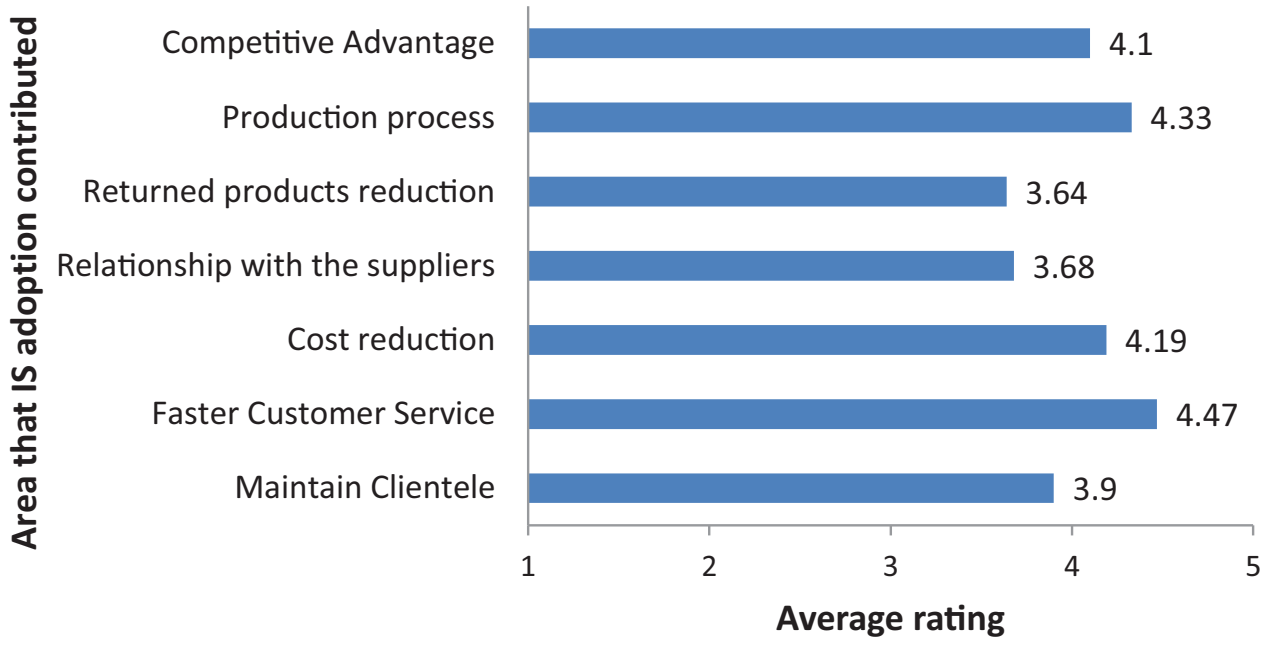

Figure 4. Contribution of IS adoption.

\subsection{Level of Profitability - Impact and Contribution of IS Adoption}

In the current section, the Mann-Whitney two-sample U-test is used to assess differences between two distinct groups that are described accordingly, regarding the impact of IS adoption and the contribution of IS adoption that were measured on the five-point Likert scale. The nonparametric test, which was mentioned above, is considered as particularly powerful for analyzing data collected in a mail survey [37]. When the $p$-value is lower than 0.05 , the U-tests indicate a significant differences between the respective two groups in each case. Otherwise, the U-tests indicate that the respective null hypothesis of no difference cannot be rejected at significance lower than 0.05 percent.

Based on the $\mathrm{H} 4$ hypothesis that the profitability of a company is positively affected by the use of IS, two prominent different groups of companies were initially identified regarding the level of profitability they were lead: those which consider that their companies manage to obtain high level of profitability due to IS adoption (IS1 $=n_{1}=36$ ) and those that obtained a medium level of profitability due to IS adoption (IS2 $=n_{2}=40$ ) [34]. According to authors in [27], if the management chooses to implement SCM, the performance of Indian SMEs can be improved on several issues including financial issues. Through this research, there is an effort to assess whether there are statistically significant differences between the two groups posing the hypotheses $\mathrm{H} 5 \mathrm{a}$ and $\mathrm{H} 5 \mathrm{~b}$.

According to the results that are shown in Figure 5, the hypothesis (H5a) of significant differences between the two groups (IS1 and IS2) according to the Mann-Whitney $U$-tests that were conducted is verified in: "Production management" ( $p$-value $=0.021)$, Distribution network management $(p$-value $=0.015)$, Warehouse management $(p$-value $=0.018)$, and Customer service ( $p$-value $=0.029)$. That means that there is a reason that IS1 companies have better average ratings compared to IS2 companies in these variables. It seems that better management in those areas led to higher profitability. There is no difference between the two groups in regards of the rest variables-Supply management and Inventory management- since the $p$-value for both is higher than 0.05 , which means that the two groups were affected in a similar way by the IS implementation regarding these two variables. 


\begin{tabular}{|c|c|c|c|}
\hline \multirow{2}{*}{$\begin{array}{l}\text { Impact of IS in the following } \\
\text { procedures }\end{array}$} & \multicolumn{2}{|c|}{ Average rating } & \multirow{2}{*}{ p-value } \\
\cline { 2 - 3 } & $\begin{array}{c}\text { High level of } \\
\text { profitability }\end{array}$ & $\begin{array}{c}\text { Profitable in relatively } \\
\text { satisfying level }\end{array}$ & 0.471 \\
\hline \hline Supply Management & 4.50 & 4.44 & 0.021 \\
\hline Production Management & 4.67 & 4.32 & 0.015 \\
\hline $\begin{array}{c}\text { Distribution Network } \\
\text { Management }\end{array}$ & 4.40 & 3.92 & 0.018 \\
\hline Warehouse Management & 4.69 & 4.42 & 0.140 \\
\hline Inventory Management & 4.69 & 4.53 & 0.029 \\
\hline Customer Service & 4.72 & 4.40 & \\
\hline
\end{tabular}

Figure 5. Impact of IS adoption-Level of profitability.

At first glance by looking at Figure 6, it is notable that high profitability is followed by a better average rating in every respective row of the table. Although with a closer look at the table and specifically the $p$-value, it is understandable that the hypothesis is not valid for every single one of the questionable elements. Production process, Returned product reduction, Relationship with the suppliers, Cost reduction and faster Customer service all have a $p$-value that is higher than 0.05 . That means that although IS1 companies have better average ratings than IS2 on those 5 elements, yet there is no significant statistical difference between these two groups, which means that they are not making such a difference that would lead in significantly higher profitability. On the other hand, there is statistically significant difference between IS1 and IS2 companies in Competitive advantage $(p$-value $=0.007)$ and Maintain clientele $(p$-value $=0.023)$, which means that the higher profitability might be a result of those companies do better in these two areas.

\begin{tabular}{|c|c|c|c|}
\hline \multirow[b]{2}{*}{ Contribution of IS } & \multicolumn{2}{|c|}{ Average rating } & \multirow[b]{2}{*}{ p-value } \\
\hline & $\begin{array}{l}\text { High level of } \\
\text { profitability }\end{array}$ & $\begin{array}{c}\text { Profitable in relatively } \\
\text { satisfying level }\end{array}$ & \\
\hline Competitive Advantage & 4.39 & 3.92 & 0.007 \\
\hline Production Process & 4.47 & 4.31 & 0.324 \\
\hline Returned Products Reduction & 3.72 & 3.59 & 0.495 \\
\hline Relationship with the Suppliers & 3.81 & 3.57 & 0.388 \\
\hline Cost Reduction & 4.33 & 4.13 & 0.102 \\
\hline Fastest Customer Service & 4.61 & 4.46 & 0.161 \\
\hline Maintain Clientele & 4.20 & 3.67 & 0.023 \\
\hline
\end{tabular}

Figure 6. Contribution of IS adoption-level of profitability.

\section{Summary, Discussion, Conclusions, and Future Research}

This empirical research addresses issues regarding which ISs that North Greek manufacturers have adopted to conduct their business, as well as the impact and contribution of IS adoption in several aspects of their business, including the cost effectiveness. During the research, 96 questionnaires were filled by North Greek manufacturing companies. Of 
those 96 responses, 83 of them use at least one IS, and those are the ones that this paper addresses more in depth. The statistical analysis of those 83 responses has led to some very interesting results.

The great majority of the companies (85.4\%) use ERP to conduct their business. That is followed by WMS (39\%), OMS (37.8\%), CRM (35.4\%), MES (25.6\%), and MRP (20.7\%) with a much lower percentage of companies that use them. The rest of the systems have a percentage of less than $14 \%$ each. Although SCM is relatively new and helps the companies to manage and organize the path a product or service needs to follow from the supplier to the customer integrating this whole chain, yet it is only used by $13.4 \%$ of the manufacturers. Even if the vast majority of them (90.4\%) have invested in an IS in the last decade, which means that most of their systems are relatively new, the majority of the respondents state that they intent to invest in a new IS in the near future.

As a general conclusion of this paper, it can be said that IS adoption has a positive impact in business-financially and nonfinancially. A main aspect that keeps business running is the profit they gain from their activities. The vast majority of the respondents $(92.7 \%)$ agree that ISs have a positive effect on their profits as they are at least satisfied of the amount they gained.

Managing a company is a challenging and difficult task. IS implementation helped the managers to improve the way they manage several business areas such as supply, production, distribution network, warehouse and inventory, as well as helping to improve their customer service. It is important that several departments of a company are able to work well individually but also as a part of the whole enterprise, communicating each other and forming a chain that would manage to deliver the product to the customers starting from their suppliers. Inventory management, Customer service and Warehouse management were more positively affected by IS adoption. On the other hand, Distribution network management was less positively affected by IS implementation. The lowest rank might be explained by the way the products are being distributed in Greece, as well as by her unique geography which contains many-big and small—islands. In mainland, the products are mostly distributed by road, as the rail network is not as modernized as of other countries (i.e., Italy). The islands make the distribution of a product a challenge because it must reach even the smallest one, which means companies must be able to take this into account when they send products there. The transportation in smaller islands is not so often, and it depends on the weather conditions, especially in the winter.

ISs also positively contributed to Faster Customer service, Production process, Cost reduction and Competitive advantage as they all have an average rating more than 4 "little positive". The respondents also stated that they managed to maintain their clientele as it is close to 4, although it does not seem like IS helped a lot with Returned products reduction and the Relationship with the suppliers.

The companies with a high level of profitability (IS1) and those with a relatively satisfying level of profitability (IS2) were compared regarding the impact of IS in several aspects of their business. Both groups assessed the impact of IS as positive with IS1 group's average ratings higher than those of IS2 group. In IS1 group, the positive impact of IS was greater in Customer service, followed by Inventory, Warehouse - the last two had same averageand Production management, while Distribution network management had the lowest average. On the other hand, in IS2 companies, the impact was more positive in Inventory management, followed by Supply and Warehouse management. Distribution network management had the lowest average slightly below 4- "little positive". Although it seems like IS1 companies have better results than IS2, in some cases, there is no statistically significant difference which means that the results are similar and the two groups of companies are affected similarly by the use of IS. Therefore, there is a statistically significant difference in Distribution network management, Warehouse management, Production management and Customer service, which means that in those situations the better results are the ones that made the difference for the IS1 companies which led them to better performance. There is no statistically significant difference to the Supply and Inventory management. 
Another comparison was held between the IS1 and IS2 companies regarding the contribution of IS implementation in certain aspects that were considered important by the authors. The IS1 companies give higher average ratings than the IS2 companies. As it was mentioned in the previous paragraph, there are cases with a statistically significant difference between the two groups and cases were there is not. A statistically significant difference occurs only in Competitive advantage and in Maintaining the Clientele between IS1 and IS2 companies. In both occasions, IS1 companies give a rating above 4 (4.32 and 4.20, respectively) while IS2 below 4 (3.92 and 3.67, respectively). It seems like IS1 companies paid more attention to improve their Competitive advantage as well as to try to maintain their customers than IS2 companies. Both companies have similar results by IS adoption in the rest (Production process, Returned products reduction, cost reduction, Relationship with the suppliers, and Faster Customer service). The two lowest average ratings for both groups are the Returned products reduction and the Relationship with the suppliers, which means that either the ISs did not help the companies to improve on those or that they paid much more attention to improve other aspects first so they did not have many resources available for those. The respondents for the IS1 companies ranked higher the Faster Customer service, Production process and Competitive advantage, while those for IS2 companies agreed on the first two, but they have as a third the Cost reduction, which was fourth for the IS1 companies. As a general conclusion, it can be said that the current research has shown that North Greek manufacturing companies use IS and they have realized that it has positive effect on their profitability. Manufacturers have also realized that IS implementation has a positive impact on the way they manage the several departments in their company. In addition, IS adoption has improved several-financial and nonfinancial-elements that help the company's strategy and performance such as competitive advantage, cost reduction, customer service, etc. In Figure 7, the authors present the total amount of the hypotheses presented into the current paper along with their validation status. At this point, the authors of this paper consider it important to acknowledge that this research was conducted under a geographical limitation since it was focused only on the manufacturing companies of North Greece and not those of the entire country. As mentioned in Section 3, the representation of the sample does not differ from the population in regards to the manufacturing sector and the district in which the company operates. Nonetheless, it would be interesting to be able to have answers from companies from the whole country. It would also be interesting to research more about the financial and nonfinancial impact of IS adoption expanding the amount of variables, so to include several other areas that might have been affected and specify even more which parts of every department were mostly affected-positively or negatively. Another research could compare some ISs to find out which one affects more several variables. 


\begin{tabular}{|c|c|c|}
\hline \multicolumn{2}{|c|}{ Hypothesis } & Validated \\
\hline \multirow{6}{*}{$\begin{array}{l}\mathrm{H}_{2}: \text { IS adoption has a positive impact } \\
\text { in: }\end{array}$} & Supply management & Yes \\
\hline & Production management & Yes \\
\hline & Distribution management & Yes \\
\hline & Warehouse management & Yes \\
\hline & Inventory management & Yes \\
\hline & Customer service & Yes \\
\hline \multicolumn{2}{|c|}{$H_{3 a}:$ IS adoption positively affected the competitive advantage } & Yes \\
\hline \multicolumn{2}{|c|}{$H_{3 b}$ IS adoption positively affected the production process } & Yes \\
\hline \multicolumn{2}{|c|}{$H_{3 c}:$ IS adoption leads to less returned products } & $\begin{array}{l}\text { Closer to median in } 5 \\
\text { points scale }\end{array}$ \\
\hline \multicolumn{2}{|c|}{$\begin{array}{l}H_{3 \mathrm{~d}} \text { : IS adoption helped the company to build a better relationship with } \\
\text { the suppliers }\end{array}$} & $\begin{array}{l}\text { Closer to median in } 5 \\
\text { points scale }\end{array}$ \\
\hline \multicolumn{2}{|c|}{$H_{3 e}:$ IS adoption leads to cost reduction. } & Yes \\
\hline \multicolumn{2}{|c|}{$H_{3 f}:$ IS adoption leads to faster customer service. } & Yes \\
\hline \multicolumn{2}{|c|}{$H_{3 g}:$ IS adoption helped the companies to maintain their clientele. } & Yes \\
\hline \multicolumn{2}{|c|}{$H_{4}:$ IS adoption has a positive impact on a company's profitability. } & Yes \\
\hline \multirow{6}{*}{$\begin{array}{l}H_{5 \mathrm{a}}: \text { "The higher the profitability, the more } \\
\text { positive the impact of IS adoption which is } \\
\text { followed by statistically significant } \\
\text { difference between the two groups (IS1 } \\
\text { and IS2) in: }\end{array}$} & Supply management & No \\
\hline & Production management & Yes \\
\hline & $\begin{array}{l}\text { Distribution network } \\
\text { management }\end{array}$ & Yes \\
\hline & Warehouse management & Yes \\
\hline & Inventory management & No \\
\hline & Customer service & Yes \\
\hline \multirow{7}{*}{$\begin{array}{l}H_{5 b} \text { : "The higher the profitability the more } \\
\text { positive the contribution of IS adoption } \\
\text { which is followed by statistically } \\
\text { significant difference between the two } \\
\text { groups (IS1 and IS2) in: }\end{array}$} & Competitive advantage & Yes \\
\hline & Production process & No \\
\hline & Returned products reduction & No \\
\hline & $\begin{array}{l}\text { Relationship with the } \\
\text { suppliers }\end{array}$ & No \\
\hline & Cost reduction & No \\
\hline & Fastest Customer service & No \\
\hline & Maintain clientele & Yes \\
\hline
\end{tabular}

Figure 7. The hypotheses presented and their validation status.

Author Contributions: Formal analysis, P.K. and S.A.; Investigation, P.K.; Methodology, P.K.; Resources, A.K.; Software, A.K. and S.A.; Supervision, S.A. All authors have read and agreed to the published version of the manuscript.

Funding: This research received no external funding.

Institutional Review Board Statement: Not applicable.

Informed Consent Statement: Not applicable.

Data Availability Statement: Not applicable.

Conflicts of Interest: The authors declare no conflict of interest.

\section{References}

1. Anastasiadou, S.; Karakos, A. The beliefs of electrical and computer engineering students' regarding computer programming. Int. J. Technol. Knowl. Soc. 2011, 7, 37-52. [CrossRef]

2. Anastasiadou, S.; Kofou, I. Incorporating Web 2.0 Tools into Greek Schools. Int. J. Technol. Learn. 2013, $20,11-23$.

3. Giotopoulos, I.; Kontolaimou, A.; Korra, E.; Tsakanikas, A. What drives ICT adoption by SMEs? Evidence from a large-scale survey in Greece. J. Bus. Res. 2017, 81, 60-69. [CrossRef]

4. Tantalaki, N.; Souravlas, S.; Roumeliotis, M. Data-Driven Decision Making in Precision Agriculture: The Rise of Big Data in Agricultural Systems. J. Agric. Food Inf. 2019, 20, 344-380. [CrossRef]

5. Tantalaki, N.; Souravlas, S.; Roumeliotis, M.; Katsavounis, S. Pipeline-Based Linear Scheduling of Big Data Streams in the Cloud. IEEE Access 2020, 8, 117182-117202. [CrossRef]

6. Souravlas, S.; Anastasiadou, S. Pipelined Dynamic Scheduling of Big Data Streams. Appl. Sci. 2020, 10, 796. [CrossRef]

7. Souravlas, S.; Anastasiadou, S.; Katsavounis, S. More on Pipelined Dynamic Scheduling of Big Data Streams. Appl. Sci. 2021, 11, 61. [CrossRef]

8. Kanellou, A.; Spathis, C. Accounting benefits and satisfaction in an ERP environment. Int. J. Account. Inf. Syst. 2013, 14, 209-234. [CrossRef] 
9. Bose, I.; Pal, R.; Ye, A. ERP and SCM systems integration: The case of a valve manufacturer in China. Inf. Manag. 2008, 45, 233-241. [CrossRef]

10. Botsiou, M.; Dagdilelis, V. Aspects of Incorporation of ICT in the Greek Agricultural Enterprises: The Case of a Prefecture. Procedia Technol. 2013, 8, 387-396. [CrossRef]

11. Cheng, C.; Chien, M.; Lee, C. ICT diffusion, financial development and economic growth: An international cross-country analysis. Econ. Model. 2021, 94, 662-671. [CrossRef]

12. Rouhani, S.; Mehri, M. Empowering benefits of ERP systems implementation: empirical study of industrial firms. J. Syst. Inf. Technol. 2018, 20, 54-72. [CrossRef]

13. Shatat, A.S.; Udin, Z.M. The relationship between ERP system and supply chain management performance in Malaysian manufacturing Companies. J. Enterp. Inf. Manag. 2012, 25, 576-604. [CrossRef]

14. Fuchs C.; Beck, D.; Lienland, B.; Kellner, F. The role of IT in automotive supplier supply chains. J. Enterp. Inf. Manag. 2018, 31, 64-88. [CrossRef]

15. Anagnostopoulos, D.; Papadopoulos, T.; Stamati, T.; Balta, M.E. Policy and Information Systems Implementation: The Greek Property Tax Information System Case. Inf. Syst. Front. 2020, 22, 791-802. [CrossRef]

16. Souravlas, S.; Anastasiadou, S.; Katsavounis, S. A Survey on the Recent Advances of Deep Community Detection. Appl. Sci. 2021, 11, 7179. [CrossRef]

17. Loukis, E.N.; Sapounas, I.A.; Milionis, A.E. The effect of hard and soft information and communication technologies investment on manufacturing business performance in Greece-A preliminary econometric study. Telemat. Inform. 2009, 26, 193-210. [CrossRef]

18. Strassman, P. The Squandered Computer; The Information Economic Press: New Canaan, CT, USA, 1997.

19. Stolarick, K. IT Spending and Firm Productivity: Additional Evidence from the Manufacturing Sector; Center for Economic Studies Working Paper CES 99-10; Bureau ofthe Census: Washington, DC, USA, 1999.

20. Katerattanakul, P.; Hong S.; Lee J. Enterprise resource planning survey of Korean manufacturing firms. Manag. Res. News 2006, 29, 820-837. [CrossRef]

21. Kannabiran, G.; Dharmalingam, P. Enablers and inhibitors of advanced information technologies adoption by SMEs: An empirical study of auto ancillaries in India. J. Enterp. Inf. Manag. 2012, 25, 186-209. [CrossRef]

22. Su Y.-F.; Yang, C. Why are enterprise resource planning systems indispensable to supply chain management? Eur. J. Oper. Res. 2010, 203, 81-94. [CrossRef]

23. Hwang D.; Min, H. Identifying the drivers of enterprise resource planning and assessing its impacts on supply chain performances. Ind. Manag. Data Syst. 2015, 115, 541-569. [CrossRef]

24. Barbosa, D.H.; Musetti, A.M. Logistics information systems adoption: an empirical investigation in Brazil. Ind. Manag. Data Syst. 2010, 110, 787-804. [CrossRef]

25. Ata Zeynep, U.; Toker A. The effect of customer relationship management adoption in business-to-business markets. J. Bus. Ind. Mark. 2012, 27, 497-507. [CrossRef]

26. Ageron, B.; Gunasekaran, A.; Spalanzani, A. IS/IT as supplier selection criterion for upstream value chain. Ind. Manag. Data Syst. 2013, 113, 443-460. [CrossRef]

27. Kumar, R.; Singh, R.K.; Shankar, R. Critical success factors for implementation of supply chain management in Indian small and medium enterprises and their impact on performance. Indian Inst. Manag. Bangalore 2015, 27, 92-104.

28. Tripathy, S.; Aich, S.; Chakraborty, A.; Lee, G.M. Information technology is an enabling factor affecting supply chain performance in Indian SMEs: A structural equation modeling approach. J. Model. Manag. 2016, 11, 269-287. [CrossRef]

29. Arvanitis, S.; Loukis, E.; Diamantopoulou, V. The effect of soft ICT capital on innovation performance of Greek firms. J. Enterp. Inf. Manag. 2013, 26, 679-701. [CrossRef]

30. Ketikidis, P.H.; Koh, S.C.L.; Dimitriadis, N.; Gunasekaran, A.; Kehajova, M. The use of information systems for logistics and supply chain management in South East Europe: Current status and future direction. Omega 2008, 36, 592-599. [CrossRef]

31. Shi, M.; Yu, W. Supply chain management and financial performance: Literature review and future directions. Int. J. Oper. Prod. Manag. 2013, 33, 1283-1317. [CrossRef]

32. Galy, E.; Sauceda, M.J. Post-implementation practices of ERP systems and their relationship to financial performance. Inf. Manag. 2014, 51, 310-319. [CrossRef]

33. Hendricks, K.B.; Singhal, V.R.; Stratman, J.K. The impact of enterprise systems on corporate performance: a study of ERP, SCM and CRM system implementations. J. Oper. Manag. 2007, 25, 65-82. [CrossRef]

34. Kapetanopoulou, P.; Kouroutzi, A. An Empirical Study of Drivers, Barriers, and Cost Efficiency of Information Systems in Greek Industry. Appl. Sci. 2021, 11, 3475. [CrossRef]

35. ICAP's Greek Financial Directory. 2017. Available online: http://www.icap.gr (accessed on 19 February 2019).

36. Cooper, D.R.; Schindler, P.S. Business Research Method, 11th ed.; McGraw-Hill: New York, NY, USA, 2011.

37. General Commercial Registry. Available online: http:/ / www.businessportal.gr/home/index_en (accessed on 25 February 2019).

38. Exporters' Association of Northern Greece. Available online: https:/ /www.seve.gr/en/ (accessed on 14 March 2019).

39. Sheskin, D. Handbook of Parametric and Nonparametric Statistical Procedures, 4th ed.; Chapman \& Hall: New York, NY, USA, 2007. 
40. Anastasiadou, S.; Anastasiadis, L.; Vandikas J.; Angeletos, T. Implicative statistical analysis and Principal Components Analysis in recording students' attitudes toward electronics and electrical constructions subject. Int. J. Technol. Knowl. Soc. 2010, 16, 341-356.

41. Anastasiadou, S.; Anastasiadis, L; Angeletos, T.; Vandikas, J. A Multidimensional Statistical Analysis of Students' Attitudes toward Physics. Int. J. Divers. Organ. Commun. Nation 2010, 16, 341-356.

42. Anastasiadou, S.; Anastasiadis, L. Reliability and validity testing of a new scale for monitoring attitudes toward electronics and electrical constructions subject. Int. J. Appl. Sci. Technol. 2011, 1, 1-10.

43. Anastasiadou, S. Evaluating a structural equation model measuring lifelong learning and continuing education factors. Int. J. Knowl. Cult. Change Manag. 2012, 12, 21-34. [CrossRef]

44. Anastasiadou, S. Diversifications between expected and perceived attitudes toward learning statistics with technology. Int. J. Learn. 2012, 18, 161-176.

45. Theodoridou, E.; Alevriadou, A.; Semoglou, A.; Anastasiadou, S. Investigating Memory Strategies and Motor Memory in Dyslexic and Non-dyslexic Children. Int. J. Learn. Divers. Identities 2014, 20, 25-44. [CrossRef]

46. Garson, D. Validity E Reliability, 2016 Edition; Statistical Associates Publishing: Asheboro, NC, USA, 2016.

47. Anastasiadou, S. Comparison of Contemporary Advanced Statistical Methods Regarding Construct Validity Evaluation of TEIque-SF Instrument: Statistical Implicative Analysis vs. Principal Components Analysis; Theme Colloque International sur Analyse Statistique Implicative (ASI 10): Belfort, France, 2019; pp. 148-163.

48. Hsu, C.C.; Kannan, V.R.; Tan, K.C.; Leong, G.K. Information sharing, buyer-supplier relationships, and firm performance. Int. J. Phys. Distrib. Logist. Manag. 2008, 38, 296-310. [CrossRef] 